Revista Tecné, Episteme y Didaxis: TED. Año 2014, Número Extraordinario. ISSN Impreso: 0121-3814, ISSN web: 2323-0126

Memorias, Sexto Congreso Internacional sobre Formación de Profesores de Ciencias. 08 al 10 de octubre de 2014, Bogotá

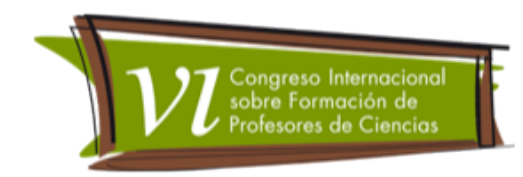

\title{
Influencia del enfoque pedagógico del currículo de la escuela normal superior Distrital María Montessori en la formación de estudiante de secundaria
}

Garzón, Lida'. Osorio, Karen². Camelo, Diego. ${ }^{3}$

Categoría 2. Trabajo de investigación (concluido)

\section{Resumen}

El escrito se fundamenta en una revisión curricular desde lo planteado y lo ejecutado en la Escuela Normal Superior Distrital María Montessori, cuyo fin es evidenciar los alcances positivos y negativos del enfoque pedagógico. Los parámetros tenidos en cuenta para la revisión se remiten a la relación que mantienen docentes y estudiantes, la cual vincula varios procesos educativos entre los cuales se enfatiza en la evaluación y el proceso de enseñanza dirigida por el docente. Como respuesta a este seguimiento se tiene que la evaluación en la escuela no ha logrado transgredir las barreras de la educación tradicional, resumiéndose en una cuestión sumativa, que cumple vagamente con lo expuesto en la educación constructivista. Así mismo el manejo de las sesiones por parte del docente, resulta atractiva a los estudiantes, sin embargo puede ser más productiva.

\section{Palabras clave}

Plan de estudios, escuela normalista, evaluación.

\section{Objetivos}

\section{General}

Examinar a través de las propuestas curriculares la correlación que tienen la evaluación aplicada y las sesiones dirigidas por los profesores, en la formación integral de ciudadanos.

Específicos

IUniversidad Distrital Francisco José de Caldas.-Bogotá-Colombia. lidamileidyg@gmail.com

2Universidad Distrital Francisco José de Caldas.-Bogotá- Colombia. kami-veg@hotmail.com

3 Universidad Distrital Francisco José de Caldas.-Bogotá- Colombia. licdiegocamelo@outlook.com 
Revista Tecné, Episteme y Didaxis: TED. Año 2014, Número Extraordinario. ISSN Impreso: 0121-3814, ISSN web: 2323-0126

Memorias, Sexto Congreso Internacional sobre Formación de Profesores de Ciencias. 08 al 10 de octubre de 2014, Bogotá

Determinar a partir de la observación los componentes de una clase diseñada para docentes en formación.

Revisar la influencia de los componentes curriculares de la ENSDMM en el ejercicio docente.

Vislumbrar las percepciones de los estudiantes acerca de los objetivos de la educación planteada en la Escuela Normal Superior Distrital María Montessori.

\section{Marco Teórico}

\section{Currículo}

Zais (1976) señala que el término "currículum" es usado ordinariamente por los especialistas de dos maneras: a) para indicar un "plan" para la educación de los alumnos/as; y b) para identificar un campo de estudios.

En general cuando el concepto de currículum significa planificación, inevitablemente se asume que en él viene resumido y establecido explícitamente el marco dentro del cual se desarrollará la actividad educativa de una escuela. El currículum es entonces, como afirma Beauchamp (1972, 1981, 1982; Conran y Beauchamp, 1975) es un documento escrito en el que se representa "el alcance y la organización del programa educativo proyectado para una escuela".

Ahora, en un sentido global la escuela plantea, basada en los paradigmas de su sociedad, metas y contenidos pertinentes para sus estudiantes y la sociedad en la que están inmersos; estrategias pedagógicas y terapéuticas enfocadas a lograr una comprensión integral de los procesos en juego en todo acto educativo que dé a los actores educativos la posibilidad de otorgarle sentido a su quehacer cotidiano. En cuanto a los objetivos y metas de una institución educativa, estos se formulan de forma general como misión y visión y, desde allí se desarrollan los demás componentes curriculares.

Para el caso de la Ensdmm la misión y visión estipuladas en el manual de convivencia son las siguientes

1.1. Misión: La Escuela Normal Superior Distrital María Montessori, desde su enfoque pedagógico está comprometida con la formación integral de maestro y maestras con pensamiento crítico investigativo, capaces de actuar y transformar responsablemente y creativamente sobre el entorno con calidad y pertenencia. 
Revista Tecné, Episteme y Didaxis: TED. Año 2014, Número Extraordinario. ISSN Impreso: 0121-3814, ISSN web: 2323-0126 Memorias, Sexto Congreso Internacional sobre Formación de Profesores de Ciencias. 08 al 10 de octubre de 2014, Bogotá

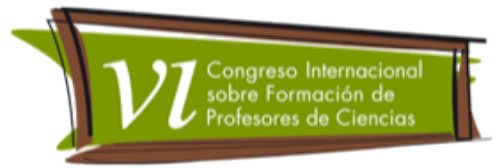

1.2. Visión: En el 2014 la Escuela Normal Superior Distrital María Montessori, será una institución educativa líder en la construcción del "ser maestro" que a través de la problematización de la enseñanza promueve el desarrollo de comunidades académicas.

1.3. El plan de estudios es el esquema estructurado de las áreas obligatorias y fundamentales y de áreas optativas con sus respectivas asignaturas que forman parte del currículo de los establecimientos educativos.

El Plan de Estudios de la Escuela Normal tiene como fundamento promover la reflexión orientada al ejercicio investigativo como herramienta inherente a la profesión docente para posibilitar la innovación del trabajo pedagógico y cualificar su quehacer como maestro.

Tabla1. Plan de estudios escuela normal superior distrital María Montessori, manejado en el programa de articulación curricular

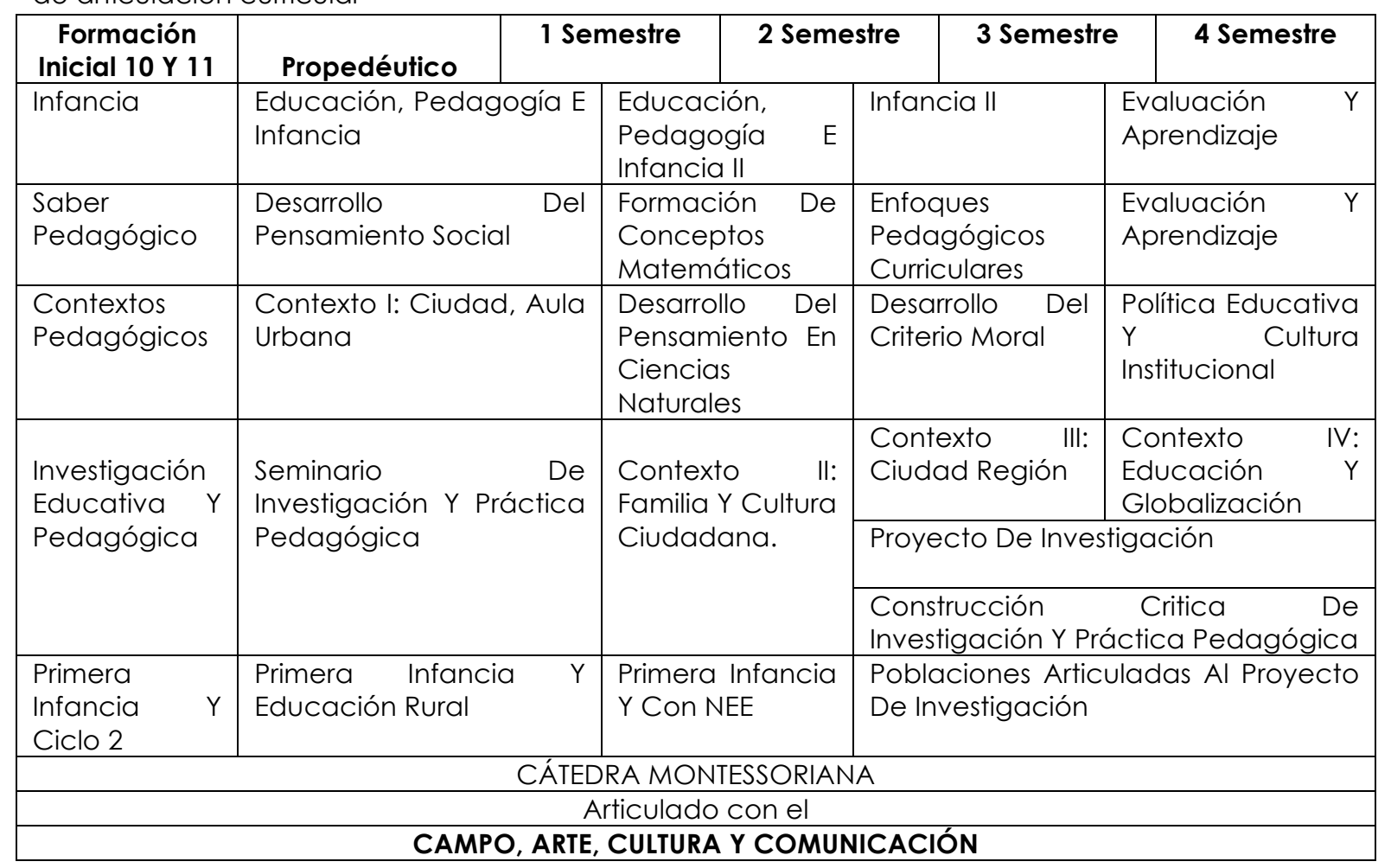

\section{Evaluación}

La evaluación según el Ministerio de Educación Nacional Colombiano, como una actividad intencionada que conduce a la reflexión sobre la acción cimentada en procedimientos y técnicas de recolección de información y sustentada en su 
Revista Tecné, Episteme y Didaxis: TED. Año 2014, Número Extraordinario. ISSN Impreso: 0121-3814, ISSN web: 2323-0126

Memorias, Sexto Congreso Internacional sobre Formación de Profesores de Ciencias. 08 al 10 de octubre de 2014, Bogotá

análisis e interpretación, que tiene como propósito realizar valoraciones fundamentadas y comunicables sobre las acciones, sus procesos y sus resultados.

Por esto se concibe como uno de los procesos más importantes, se visualiza como un paso de monitoreo continuo, participativo, secuencial, de observación sobre los procesos de aprendizaje, las potencialidades, los avances, las dificultades y las interferencias que va presentando el estudiante y la problematización de la enseñanza.

La evaluación que plantea el proyecto educativo institucional (PEI) en la ENSMM, se enfoca en tres parámetros el pensar, el conocer y el actuar. Según lo estipulado es una evaluación completa que busca resaltar todos los aspectos que intervienen en el proceso educativo.

\section{Proceso de enseñanza dirigida por el docente}

La formación docente debería estar orientada al desarrollo de profesores autónomos, críticos, reflexivos e investigadores con competencias comunicativas, tanto en el lenguaje oral como escrito, con capacidades para tomar decisiones y actuar bajo la incertidumbre, así lo exigen la multiplicidad de elementos que confluyen en los espacios educativos. Vista desde la complejidad del escenario escolar, surge la necesidad de un educador competente para potenciar las capacidades de cada ser humano, entre ellas, el pensamiento de los niños y niñas que asisten a las escuelas básicas. Por tanto, el docente debe poseer competencias para pensar de manera crítica y reflexiva, desde una perspectiva problematizadora, exponer situaciones y encontrar soluciones.

En otras palabras, se requiere un docente con pensamiento crítico, promotor de acciones para comprender y cuestionar la realidad y ayudar a transformarla para el bien común. Esto indica que puedan comprender la complejidad del aula y el contexto escolar.

\section{Metodología}

Los instrumentos empleados para lograr dicho análisis, fueron entrevistas, encuestas y diarios de clase, que en conjunto son representativas de una investigación etnográfica, en la cual se llevó a cabo un trabajo no participativo. La entrevista se aplicó a docentes y estudiantes, las preguntas allí consignadas indagaron acerca de las concepciones sobre currículo, actividades institucionales y relaciones entre profesores y estudiantes. Los diarios de clase por su parte, 
Revista Tecné, Episteme y Didaxis: TED. Año 2014, Número Extraordinario. ISSN Impreso: 0121-3814, ISSN web: 2323-0126

Memorias, Sexto Congreso Internacional sobre Formación de Profesores de Ciencias. 08 al 10 de octubre de 2014, Bogotá

guardan información detallada de las observaciones hechas en cada visita al aula, por parte de los investigadores.

\section{Resultados}

Se realizó la observación a los grados 10 y 11 de la ENSDMM, en el espacio de la clase de Química. Los grupos constan por lo general, de un número superior a 25 estudiantes. Al ser una de las dos Escuelas Normales Distritales de Bogotá, su currículo, y por ende el plan de estudios, proporcionan a los estudiantes de los grados mencionados, una visión pedagogía más marcada y con un propósito claro.

Las clases de química de los estudiantes reflejan una enseñanza poco problematizada ya que se presentan en ocasiones repetidas ejercicios de lápiz y papel de resolución mecánica que inicialmente indican al estudiante respuestas y procedimientos únicos. Sin embargo, la institución implementa proyectos transversales desde cada área del saber, como el PRAE y el uso de las TICS, que invitan al estudiante a poner en práctica y articular los saberes aprendidos en las diferentes asignaturas para responder a una necesidad de la comunidad educativa, es decir que en este sistema educativo confluyen varias estrategias de enseñanza que posibilitan un mejor desarrollo del ciudadano.

La actividad docente se vale de previas y evaluaciones para identificar conocimiento de tipo memorístico, utilizando la escala evaluativa de 1 a 5 , asignando el menor valor a 1, y 5 al mejor a las mejores respuestas. La carga académica que incluye todo el enfoque pedagógico de la normalista, debe considerar ampliar el tiempo de preparación docente, debido a la presencia de bastantes asignaturas en un solo semestre alrededor de 1 para el grado 10, está situación dificulta el estilo de vida de los estudiantes sus hábitos académicos y se refleja en la famosa "mortalidad del primer semestre", ya que muchos estudiantes lo pierden por confiados, como afirman ellos mismos, según entrevistas. La exigencia que propone el colegio, no es percibida como una manera de generar un estilo de vida más relacionado con la investigación y la academia.

Las categorías de evaluación que maneja la institución aunque bien planteadas son hoy un blanco de reflexión, pues su aplicabilidad se torna insignificante. El diario de clase relaciona la evaluación como un proceso con que mantiene influencias de la evaluación tradicional, básicamente por la presencia de las notas cualitativas. El alumno no dimensiona el poder del conocimiento, omite que este le sirve para su formación social y le permite dar soluciones a problemas comunes. 
Revista Tecné, Episteme y Didaxis: TED. Año 2014, Número Extraordinario. ISSN Impreso: 0121-3814, ISSN web: 2323-0126

Memorias, Sexto Congreso Internacional sobre Formación de Profesores de Ciencias. 08 al 10 de octubre de 2014, Bogotá

Cuando la evaluación persigue ese camino de lo tradicional, disminuye la posibilidad de que los alumnos que están en formación, reproduzcan la evaluación constructivista que es una de características que busca la educación constructivista.

El aula en general maneja un ambiente particular, de entrada se reconoce que la visión que poseen de ser docente, favorece el trabajo de apropiación de conocimientos. Un estudiante desarrollado en un ambiente en el cual podrá aspirar a ser docente, lo hace más receptivo, menos disperso y más respetuoso con sus semejantes.

Por su parte el plan de estudios considera materias exclusivas para el desarrollo curricular de la escuela normalista. Durante las sesiones no se evidencia que el docente enseñe a sus estudiantes a enseñar. Por lo que la misión presentaría falencias en la formación de maestros. Realmente existe una desarticulación entre enseñarles pedagogía y enseñar con pedagogía.

En el transcurso de las sesiones de laboratorios los estudiantes son frecuentemente pasivos frente a las instrucciones dadas por el docente y los resultados que obtienen de la práctica, por lo que la actitud crítica que busca desarrollar la institución y que especifica en su visión, no se evidencia en su totalidad. Además, de acuerdo con las entrevistas realizadas a los estudiantes, su desarrollo crítico e investigativo es fomentado exhaustivamente a partir del tercer ciclo en asignaturas como seminario investigativo y saber pedagógico. De esta manera el trabajo de la escuela normalista cae bajo un modelo de reproducción en el cual no se cultivan las cualidades propias de un docente comprometido con la formación de personas.

\section{Conclusiones}

Desde la revisión curricular expuesta principalmente desde la visión y la misión planteadas por la institución, se encuentran que el sentido crítico presenta debilidades, propias de la sociedad en la cual se desarrollan una gran mayoría de los adolescentes en formación.

El plan de estudios considerado, a pesar de contener asignaturas propias para la formación docente está descuidando el ejemplo de ser maestro. Es decir la Escuela en las sesiones de química no permite evidenciar una educación para educadores. Adicionalmente, los parámetros de evaluación son bastante rígidos al ser sumativa y no considerar un tipo de evaluación más flexibles y cualitativa, 
Revista Tecné, Episteme y Didaxis: TED. Año 2014, Número Extraordinario. ISSN Impreso: 0121-3814, ISSN web: 2323-0126

Memorias, Sexto Congreso Internacional sobre Formación de Profesores de Ciencias. 08 al 10 de octubre de 2014, Bogotá

teniendo en cuenta, que lo que importa no es la cantidad sino la calidad de los conocimientos adquiridos.

\section{Referencias bibliográficas}

S. Zais.(1976). Curriculum: Principles and Foundations. New York. The University of Chicago Press.

Beauchamp, G.A. (1972). Basic Components of a Curriculum Theory. En Bellack, A.A y Kliebard, H.M. (Eds) (1977). Curriculum and Evaluation. Bekerley: McCutchan.

Ministerio de Educación Nacional, República de Colombia. Plan de Estudios. Recuperado de http://www.mineducacion.gov.co/1621/article-79419.html.

Martínez E., Salanova S. (2004). Los Métodos De Enseñanza. Recuperado de http://www.uhu.es/cine.educacion/didactica/0031 clasificacionmetodos.ht $\mathrm{ml}$

Barriga F, Fernandez G. Estrategias docentes para un aprendizaje significativo: Una interpretación constructivista. Recuperado de http://www.urosario.edu.co/CGTIC/Documentos/estategias_docentes.pdf

María Auxiliadora Chacón Corzo. (2008.) Las estrategias de enseñanza reflexiva en la formación inicial docente. Recuperado de http://www.scielo.org.ve/scielo.php?pid=\$1316$49102008000200007 \&$ script=sci_arttext 